European continent.

The team says that its findings support the idea that Britain's first Anglo-Saxons were locals who rapidly shifted cultures after the fall of Roman Britain.

J. Arch. Sci. 42, 81-92 (2014)

ANIMAL BEHAVIOUR

\section{Lizards socialize} to thrive

Social isolation in early life could impair the development of reptiles, according to a study of chameleons.

Social behaviour is well documented in mammals and birds, but it is not so firmly corroborated in coldblooded vertebrates. Cissy Ballen and her colleagues at the University of Sydney in Australia compared the social interactions of veiled chameleon (Chamaeleo calyptratus) hatchlings raised in isolation with those raised in a group setting. The authors found that socialized lizards were less submissive, displayed brighter and more saturated colours when encountering new chameleons, and captured food more quickly than did lizards raised in isolation.

The findings add to evidence challenging the conventional view that reptiles are capable of only simple social behaviour. Anim. Behav. http://doi.org/q9h (2014)

\section{EVOLUTIONARY BIOLOEY}

\section{Night life fosters foul sprays}

Carnivores that spray foul anal secretions might have evolved this ability in response to night-time predation from other mammals.

Theodore Stankowich at California State University in Long Beach and his colleagues looked at the behaviour of 181 species of carnivorous mammals and their predators. The authors found that carnivores are targeted mainly by other mammals at night and by birds of prey during the day. Animals that are active during the day are more likely to develop tight-knit social groups that are better at detecting and warding off predators.

Nocturnal animals cannot rely on early visual detection and instead use short-range defence systems such as noxious sprays, which are more effective against other mammals than against birds. Evolution http://doi.org/q9w (2014)

\section{NEUROSCIENCE}

\section{Pruning problems alter brain wiring}

Abnormal pruning of neuronal connections might stall brain maturation, resulting in reduced brain connectivity and even behaviours linked to disorders such as autism.

Cornelius Gross at the European Molecular Biology Laboratory in Monterotondo, Italy, and his colleagues studied mice that were engineered to have fewer microglia - nonneuronal brain cells that trim back synapses, or neuronal connections, during brain development. These animals had fewer synapses between neurons and decreased connectivity between brain regions, and seemed to be less social in behavioural tests.

Microglia and synaptic pruning are important for normal brain development, and problems with this pruning could lead to neurodevelopmental disorders, the authors say.

Nature Neurosci.

http://doi.org/rbf (2014) ASTRONOMY

\section{How big galaxies died fast}

Astronomers have worked out the origin of giant galaxies that seemed to have fizzled early in the Universe's history, just three billion years after the Big Bang.

To find out how massive elliptical galaxies became so big and stopped forming stars so quickly, Sune Toft of the Niels Bohr Institute

COMMUNITY CHOICE

The most viewed papers in science

CLIMATE CHANGE

\title{
United States tops warming list
}

HIGHLY READ
on iopscience.iop.org
29 Dec-28 Jan

Damon Matthews and his colleagues at Concordia University in Montreal, Canada, analysed the national emissions of greenhouse gases and aerosols, including those from land use, between 1800 and 2005. They calculated that a total warming of $0.7^{\circ} \mathrm{C}$ occurred during this period, and that more than $21 \%$ of this total is linked to the United States. China and Brazil exceed the United States slightly in terms of their contributions from land-use activities, such as deforestation and agriculture, but the high level of cumulative US fossil-fuel use makes the country the biggest contributor overall.

Among the major emitters, the United Kingdom and the United States top the rankings on a per capita basis, with contributions that are more than ten times higher than those of either China or India.

Environ. Res. Lett. 9, 014010 (2014)

in Copenhagen and his colleagues compared samples of these dead galaxies and an earlier generation of starforming ones observed with the Hubble, Herschel and Spitzer space telescopes. The authors conclude that earlier, gas-rich galaxies merged, kicking off intense star formation that rapidly used up all the gas, resulting in the large, burnt-out galaxies.

Astrophys. J. 782, 68 (2014)

\section{MATERIALS}

\section{Tiny cracks toughen up glass}

Glass etched with intricate micropatterns is much tougher than normal glass, report Francois Barthelat and his colleagues at McGill University in Montreal, Canada.

The researchers were inspired by natural materials such as tooth enamel and nacre in mollusc shells, which are stiff and hard, but not brittle. In these structures, cracks are unable to spread rapidly because they are forced to travel along tortuous or

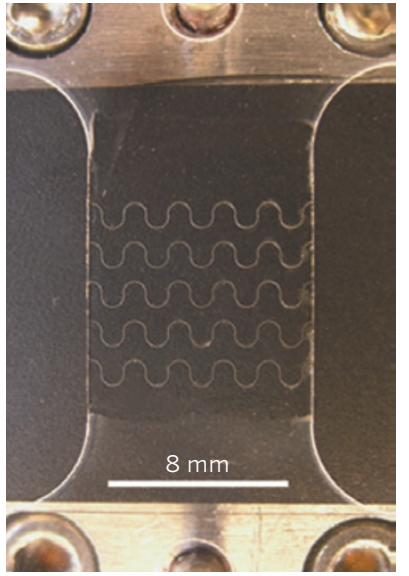

interlocking channels that are criss-crossed by proteins holding the structure together. The researchers etched similar patterns into glass (pictured) and filled in the gaps with shock-absorbent polyurethane, creating a material that is 200 times tougher than standard glass.

The approach could be used to make brittle materials such as ceramics shatter-resistant. Nature Commun. 5, 3166 (2014)

\section{$\rightarrow$ NATURE.COM}

For the latest research published by Naturevisit:

www.nature.com/latestresearch 